\title{
Activation of phenylalanine ammonia lyase as a key component of the antioxidative system of salt-challenged maize leaves
}

\section{Ashraf Gholizadeh"* and B. Baghban Kohnehrouz ${ }^{2}$}

\author{
${ }^{1}$ Research Institute for Fundamental Sciences (RIFS), University of Tabriz, Tabriz, Iran \\ ${ }^{2}$ Department of Plant Breeding and Biotechnology, University of Tabriz, Tabriz, Iran \\ *Corresponding author: Fax: 98 (411) 3294113; e-mail aghz_bioch@yahoo.co.in \\ Received: 12 April 2010; Accepted: 29 December 2010
}

\begin{abstract}
Differential antioxidative activities were assessed in the leaves of two maize inbreds (A-180 and A-619) under salt stress and the subsequent recovery period. Total antioxidation test revealed that in both inbreds, this ability was sharply increased during stress period, but was slowly reverted back to the normal level during recovery. The enzymatic antioxidative analysis showed differential patterns in the activities of catalase, peroxidase and polyphenol oxidase in both maize inbreeds. Comparative analysis of the activity of phenylalanine ammonia lyase (PAL), a key enzyme at the gateway of propanoid biosynthetic pathway, suggested that propanoid compounds might be antioxidants of pivotal importance to the salt-challenged maize antioxidation system. As for drought-stressed plants, a PAL-dependent antioxidative strategy is proposed as a promising target for maize salt resistance engineering.
\end{abstract}

Key words: Antioxidation, maize, salt stress, PAL, catalase, peroxidase, polyphenol oxidase

\section{INTRODUCTION}

Soil salinity is one of the major abiotic stresses, which reduces crop production all around the world (Schleiff, 2008). Salinity stress causes injury in plants by osmotic stress, ionic effect, nutrient deficiency, generating reactive oxygen species (ROS), thereby affecting various physiological and biochemical mechanisms associated with plant growth and development (Munns, 2002).

Production of ROS is one of the early responses to different types of environmental stresses, including the salinity (Alscher et al., 1997; Hernàndez et al., 2001; Abel et al., 2003). In plants, the overproduction of ROS may eventually cause membrane damages and multiple cellular damages affecting transcription, translation, protein activity, metabolic changes and leading to programmed cell death (Blokhina et al., 2003; Desikan et al.,
2001; Lee et al., 2007; Rental et al., 2004; Yoda et al., 2006). It has been suggested that salt effects on plant cells are mediated by an enhanced generation of ROS (Asada, 1994; Gossett et al., 1994). For protection against this ROS burst, plants have evolved adaptive antioxidative strategies to reduce oxidative damage resulting from salt stress. Salt-tolerant plants having an efficient antioxidative system for effective removal of ROS are able to regulate water, ionic relations and other salt effects, efficiently (Rout and Shaw, 2001; Saleh and Plieth, 2009).

Antioxidative system in plants is grouped into two classes consisting of enzymatic and non-enzymatic types (Adam et al., 1995; Bestwick et al., 2001). The enzymatic antioxidation is carried out by a series of redox enzymes generally catalyzing electron transfer to ROS using low molecular weight antioxidant compounds (e.g. ascorbate, tocopherol, glutathione, phenols and flavonoids) as electron and proton donors (Shoa et al., 
2007; Mittler, 2002) and by the enzymes that are involved in the synthesis and regeneration of the low molecular mass antioxidants (Larson, 1988). Non-enzymatic antioxidation has been found to be carried out by some high molecular weight compounds mostly including a number of proteins that avidly scavenge ROS and protect plants structures and functions against oxidative damages (Okada and Okada, 1998).

In general, plants with high levels of antioxidants have been reported to posse greater resistance to different types of environmental stresses including salt stress (DionisioSese and Tobita, 1998; Young and Jung, 1999; Stepien and Klobus, 2005). On the other hand, plants exhibit different types of antioxidative profiling in response to different types of environmental stresses (Saleh and Plieth, 2009). So far, no specific and conclusive profiling of antioxidive system has to our knowledge been reported for salt stress, suggesting that the antioxidative response can vary with the stress intensity and duration, combined effects of other environmental factors and plant species/varieties.

Maize is an important crop all around the world. It is well characterized by the multiplicity of its agro-industrial uses. However, in many areas of the world, its productivity is limited because of soil salinization (Hichem et al., 2009). The improvement of the maize yield potential in these areas through recombinant DNA technology approaches will requires understanding the possible adaptive mechanisms to salinity stress. The objective of this study was to elucidate the relative participation of some antioxidative components including catalase, peroxidase, polyphenol oxidase and phenylalanine ammonia lyase in salt-challenged maize plants.

\section{MATERIALS AND METHODS}

Plant growth and treatments: The grains of Zea mays $L$ (inbred lines A-180 and A-619) were provided by Dr. B. Baghban Kohnehrouz (plant genetic engineering laboratory, Department of Plant Breeding and Biotechnology, University of Tabriz, Iran). Grains were surface sterilized using $1 \% \mathrm{NaOCl}$ for 15 min and then rinsed three times in distilled water. Sterilized grains were germinated and grown till seedling stage in petri plates. The 8 days old seedlings with uniform sizes were transferred into experimental tubes containing $20 \mathrm{ml}$ of modified Hoagland nutrient solution (Gholizadeh et al., 2007). They were allowed to grow under laboratory sun light condition (day to night period of $12 \mathrm{~h}$ :
$12 \mathrm{~h}$ and humidity of about $65 \%$ ). For salt stress treatment, test plants at forth leaf stage were exposed to high salt concentrations (150 mM NaCl) for $24 \mathrm{~h}$. Then plants were reverted back to the normal non-stressed conditions and allowed for recovery for 4 days. The leaf blades were randomly harvested from different leaves of the same plant at $24 \mathrm{~h}$ time intervals and processed for further experiments. All materials are freshly analyzed and not stored in $-80^{\circ} \mathrm{C}$.

Total antioxidant power assay: The total antioxidant ability of the plant leaf materials was determined using ferric reducing antioxidant power (FRAP) assay (Benzie and Strain, 1999). To 1 $\mathrm{ml}$ of plant extract in $0.1 \mathrm{M}$ phosphate buffer (pH 7.0), $3 \mathrm{ml}$ of FRAP reagent (10 mM TPTZ: tripyridyl triazine, $20 \mathrm{mM} \mathrm{FeCl}_{3} .6 \mathrm{H}_{2} \mathrm{O}$ and $300 \mathrm{mM}$ sodium acetate buffer ( $\mathrm{pH} 3.6$ ) in the ratio of 1:1:10) were added and the reaction mixture was incubated at $37^{\circ} \mathrm{C}$ for $4 \mathrm{~min}$. The assessment was carried out spectrophotometerically at $A_{593}$. Antioxidant potential was determined against the standard curve of ferrous sulphate $(\mathrm{Fe}, 100-1000 \mu \mathrm{M})$. Ascorbic acid $(100 \mu \mathrm{M})$ was served as a positive control and BSA was used as negative control. FRAP values were calculated as follows: FRAP value $\left(\mu \mathrm{mol} 100 \mathrm{mg}^{-1}\right)=\left(A_{593}\right.$ of test sample $/ A_{593}$ of standard $)$ $\times$ FRAP value $\left(\mu \mathrm{mol} 100 \mathrm{mg}^{-1}\right)$ of standard. FRAP values of all test samples were presented as ( $\mu \mathrm{mol} F \mathrm{Fe}^{\|}$per $100 \mathrm{mg}$ leaf fresh weight). All of the samples were analyzed in duplicate and the data were presented as mean values.

Enzyme extraction: $200 \mathrm{mg}$ of leaf blades were homogenized in $1 \mathrm{ml}$ of $0.1 \mathrm{M}$ phosphate buffer $(\mathrm{pH} 7.0)$ containing $0.5 \mu$ l of $\beta$-mercaptoethanol and a pinch of polyvinyl polypyrrolidone (PVP). The homogenate was centrifuged at $12,000 \times \mathrm{g}$ for $10 \mathrm{~min}$ and the supernatant was used for redox enzymes activity assay.

Catalase activity analysis: Catalase activity was assayed according to previously described method (Sadasivam and Manickam 1992). The assessment was carried out spectrophotometrically by monitoring the changes in the $\mathrm{OD}$ values at $240 \mathrm{~nm}$. Time required for a observation of a decrease in $\mathrm{OD}$ from 0.45 to 0.40 was noted and used for calculating enzyme units. The activity of the enzyme was presented as units per mg of soluble protein.

Peroxidase activity analysis: The peroxidase activity was measured using the method as described by Sadasivam and Manikam (1992). One unit of the enzyme was considered as the amount of the enzyme that was responsible for the increase in 
OD value of 0.1 in $1 \mathrm{~min}$ at $436 \mathrm{~nm}$. The activity of the enzyme was expressed as units per mg of soluble protein.

Polyphenol oxidase activity analysis: Method of Siddique et al. (1992) was followed for the assay of polyphenol oxidase activity. The unit of enzyme activity was defined as the rate of changes in one unit absorbance per min at $420 \mathrm{~nm}$. Enzyme activity was expressed as units per mg of soluble protein.

Phenylalanine ammonia lyase activity analysis: Leaf samples (200 mg) were homogenized in $2 \mathrm{ml}$ of $25 \mathrm{~mm}$ borat buffer, pH 8.8 containing $2 \mu \mathrm{l} \beta$-mercaptoethanol and a pinch of polyvinyl polypyrrolidone (PVP). The homogenate was filtered through the cheese cloth, centrifuged at $12,000 \times \mathrm{g}$ for 10 min and the supernatant was used for enzyme activity assay according to Sadisivam and Manickam (1992). One unit of the enzyme was defined as increase in absorbance of one unit per min. The activity of the enzyme was expressed as units per mg of soluble protein.

Statistic analysis: All data in the figures represent the means \pm SE of three individual treatments with two replications per treatment. Variance analysis was analyzed by ANOVA at $p \leq$ 0.05 . Values followed by different Latin letters in each assay on the graphs are statistically different $(p \leq 0.05)$.

\section{RESULTS}

Total antioxidative capacity: In order to test the total antioxidative capacity of maize leaves, FRAP assay was performed at three different stages including before stress (days 1, 2 and 3), during stress (day 4) and recovery period (days 5,6 and 7). FRAP test is known as a simple and reproducible method used for the assessment of the total antioxidative capacities from different sources. For better assessment of the results, a control non-treated plant was also considered. The results showed that the antioxidative capacity in the leaves of maize A-180 sharply increased to $1.9 \mu \mathrm{mol} F \mathrm{Fe}^{\prime \prime} / 100 \mathrm{mg}$ during stress period (Figure 1). This property decreased slowly close to the normal level during recovery period. The total antioxidative status of leaf tissues reached up to $0.71 \mu \mathrm{mol} \mathrm{Fe} / 100 \mathrm{mg}$ after four days of recovery. Response of total antioxidative status in maize A-619 leaves showed a similar pattern as that of A-180 (Figure 1). In this plant, the FRAP value sharply increased up to $1.1 \mu \mathrm{mol} \mathrm{Fe"/100} \mathrm{mg,} \mathrm{but} \mathrm{it} \mathrm{slowly} \mathrm{declined}$ close to the level of before the stress exposure $(\sim 0.75 \mu \mathrm{mol}$
$\mathrm{Fe}$ "I100 mg), after four days of recovery. Statistical analysis showed that the FRAP values were significantly different per day $(P \leq 0.05)$. Data related to similar experiments in control (non-treated) plants revealed that the antioxidant capacity in their leaves was not significantly different during conditional shift (Figure 1).
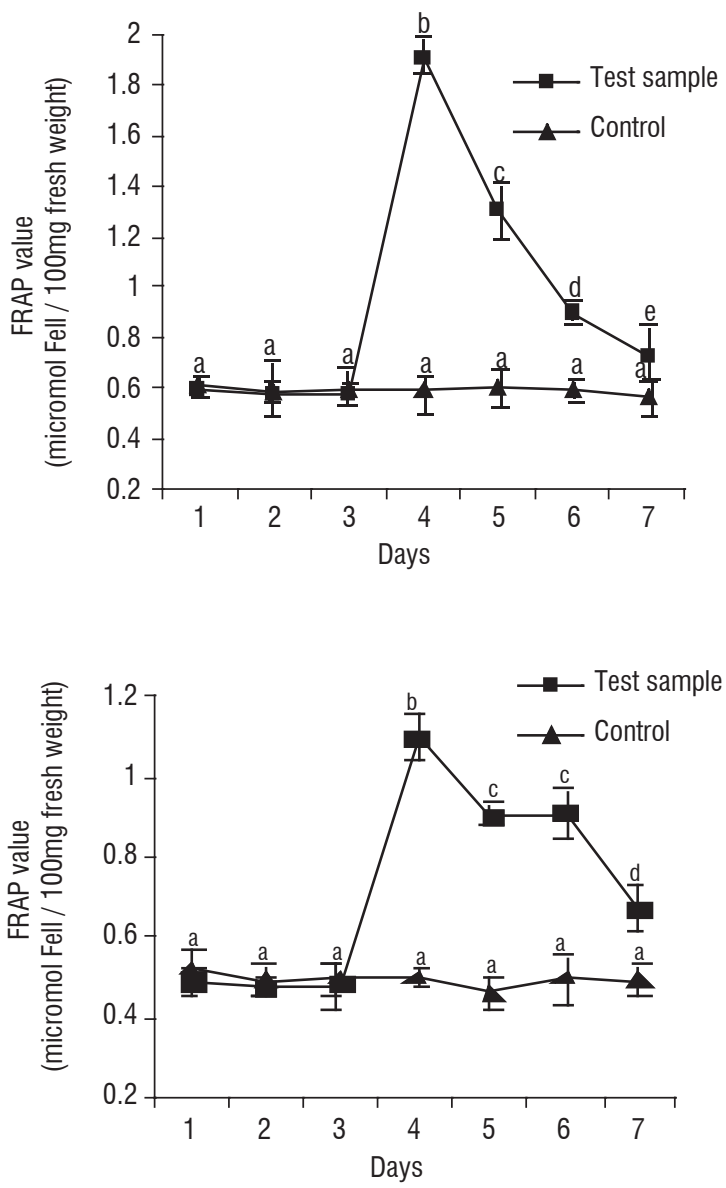

Figure 1. Total antioxidative test by FRAP. Maize A-180 (left) and A-619 (right) leaf materials were processed for their total antioxidative ability using ferric reducing antioxidant power (FRAP) test at three different stages including before stress (days 1, 2 and 3 ), during stress (day 4) and recovery period (days 5, 6 and 7). A control non-treated plant was also considered for better assessment of the results. Data were presented as the means of duplicates.

Redox enzymes activities: To explain the relative role of redox enzymes in the antioxidative system of saltchallenged maize plants, we assessed the activities of catalase, peroxidase and polyphenol oxidase. All assessments were carried out on leaf materials collected from the same plant at three different stages: $24 \mathrm{~h}$ before stress, $24 \mathrm{~h}$ after stress treatment and $24 \mathrm{~h}$ after recovery. The results revealed that during salt stress the activity of catalase increased in 
maize A-180 (Figure 2). It increased to about 0.012 and 0.001 units/ $\mathrm{mg}$ soluble protein in A-180. After $24 \mathrm{~h}$ recovery, the activity of catalase decreased to the level of before stress stage. Our results showed that catalase activity in A-619
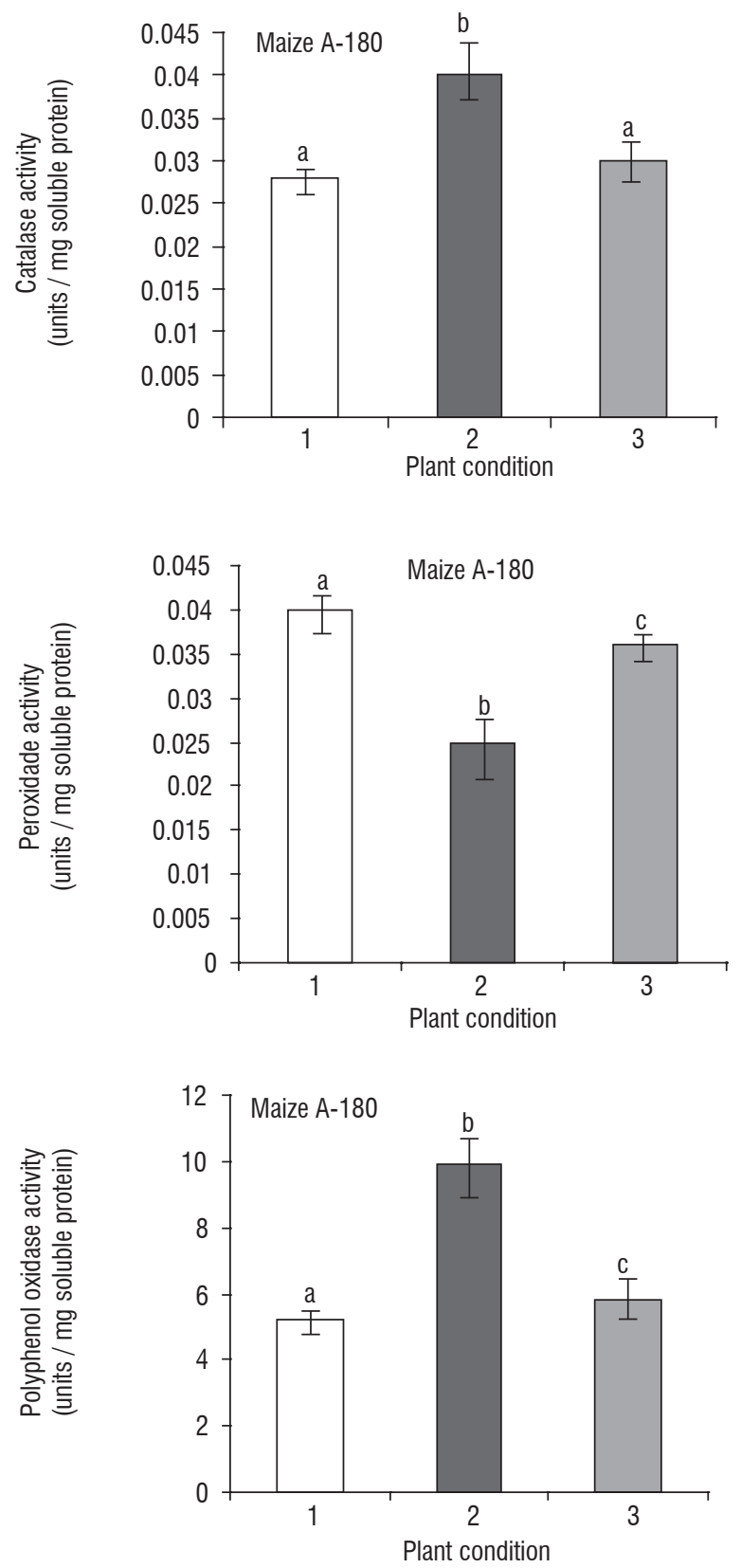

remains constant during stress and recovery period (Figure 2). Data analysis (at $P \leq 0.05$ ) showed that the antioxidant values were not significantly changed in response to the stress release.
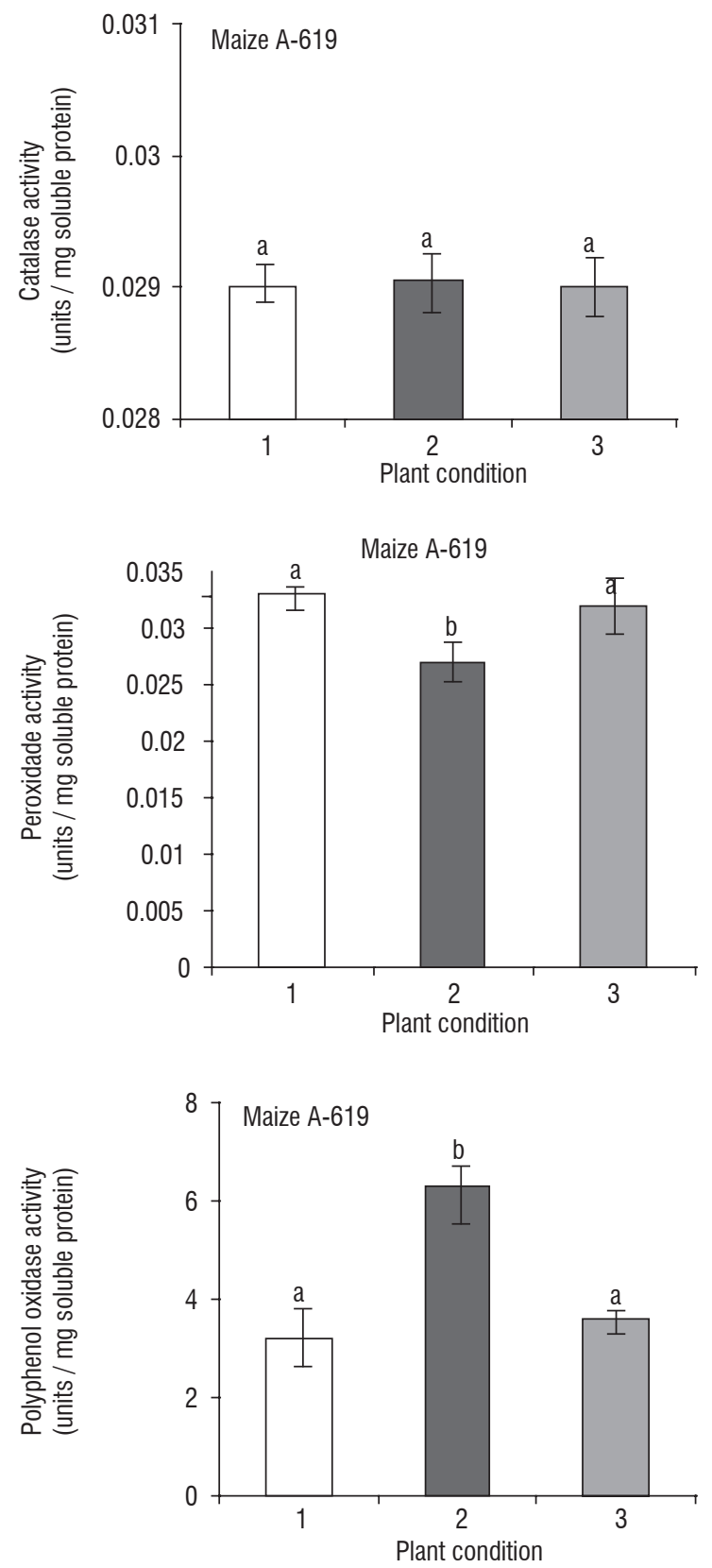

Figure 2. Enzymatic assessment of antioxidation status. The leaf blades of both maize inbreds were processed for enzymatic antioxidative status in terms of the three redox enzymes activities including catalase, peroxidase and polyphenol oxidase as described in materials and methods. The assessments were carried out at three time points including $24 \mathrm{~h}$ before stress treatment (plant condition 1), $24 \mathrm{~h}$ after stress treatment (plant condition 2) and $24 \mathrm{~h}$ after recovery (plant condition 3 ). Data were presented as the means of duplicates analyzed at $P \leq 0.05$ analyzed at $P \leq 0.05$. 
The peroxidase activity was reduced in both lines during the stress period. A decrease of about 0.015 and 0.006 units were measured for $A-180$ and $A-619$, respectively (Figure 2). Data showed that the antioxidant capacity in the leaves of maize A-180 did not reach the same level of before the stress imposition.

The activity of polyphenol oxidase enzyme was found to be enhanced up to 9.9 and 6.3 units in A-180 and A- 619 maize plants, respectively, upon salt stress for $24 \mathrm{~h}$ (Figure 2). This enzyme activity was found to recover the levels of before stress condition during $24 \mathrm{~h}$ recovery period in both maize varieties A-180 andA-619.

The overall results revealed that in contrast to the total antioxidative status of the leaves of stressed plants, for the

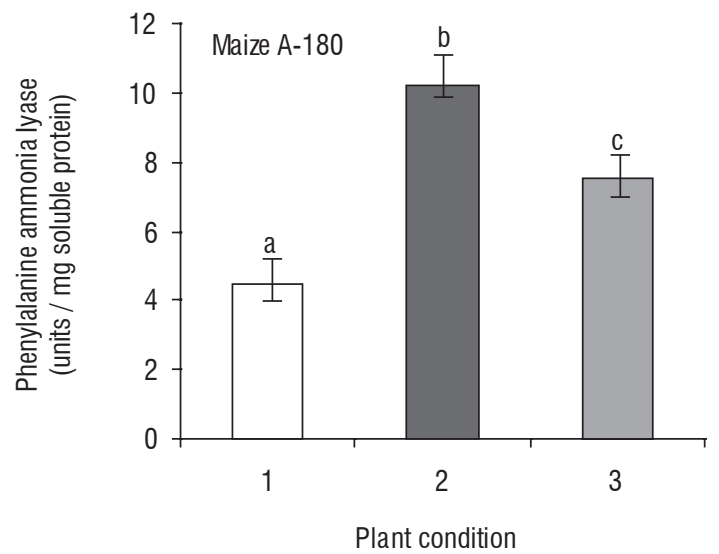

activities of catalase, peroxidase and polyphenol oxidase no significant activation or deactivation remained during recovery period in both inbred lines.

Activation of phenyl propanoid biosynthetic pathway: The results showed that activity of PAL increased quickly during one day salt stress period in both maize inbreds (Figure 3). It is increased from 4.5 to 10.2 and from 5.1 to 9.3 units on first day of stress treatment in the maize A-180 and A-619, respectively. Data showed that the PAL activities in both plants were not significantly reverted back to the levels verified before the stress, at least during the first $24 \mathrm{~h}$ after the stress release.

The overall pattern in the activity of the PAL enzyme showed similarity to the total anitioxidation pattern in maize plants under salt stress conditional shif.

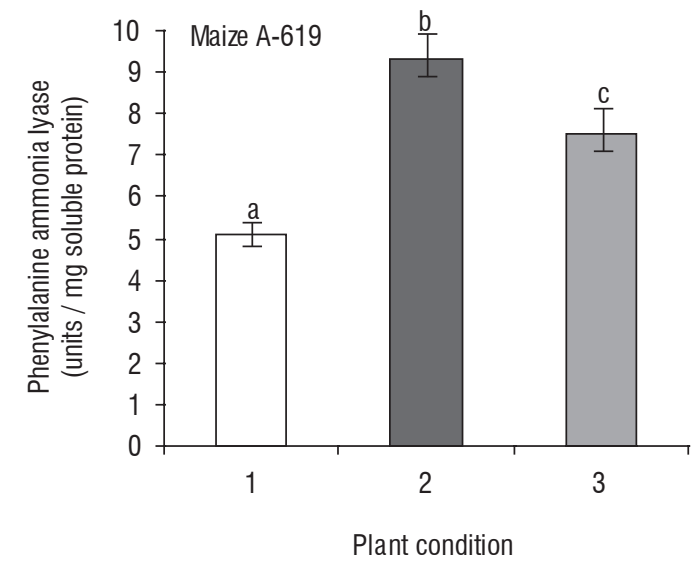

Figure 3. Assessment of the activity of phenylalanine ammonia lyase. Activation of propanoids biosynthetic pathway was assessed in terms of PAL activity analysis in both inbreds as described in materials and methods section. Experiment was carried out at three different plant conditions including $24 \mathrm{~h}$ before stress treatment (plant condition 1), $24 \mathrm{~h}$ after stress treatment (plant condition 2) and $24 \mathrm{~h}$ after recovery (plant condition 3). Data were presented as the means of duplicates analyzed at $\mathrm{P} \leq 0.05$.

\section{DISCUSSION}

Earlier studies have been shown that salt stress induces an oxidative burst in maize plants that is followed by the differential activation of their antioxidative system (Stepien and Klobus, 2005; Hichem et al., 2009; Kholova et al., 2009). Our experiments on different lines of maize confirmed these earlier results and revealed that the total antioxidative capacity of both maize lines sharply increased after the stress imposition, but it is decreased slowly close to the normal level straight after the stress release (Figure 1).
There are several reports of increase in total antioxidant capacity of different plants under salinity stress (Gossett et al., 1994; Tsugane et al., 1999; Sreenivasulu et al., 2000; Hernandez et al., 2001; Gomez et al., 2004; Niknam et al., 2006; Saleh and Plieth, 2009; Heidari, 2009). However, so far, much less attention has been given to specific patterns for the antioxidant response over the recovery periods after treatment suspension of salt stressed plants. The present study highlights the relevance of these recovery experiments to provide further assessment criteria for characterization of a resistance phenomenon. 
Antioxidative system in plants has been composed of several enzymatic and non-enzymatic components which might be affected differentially under salt stress in different plants. There have been several reports of both increase and decrease in catalase activity in different plants under salt stress (Tsugane et al., 1999; Niknam et al., 2006; Saleh and Plieth, 2009). In maize, its increase pattern has been previously reported for PEHM 3 and Navgot genotypes (Kholova et al., 2009), a characteristic suggested to be related to their salt stress resistance. Since that this pattern of activation is verified only in the maize A-180 (Figure 2) it may suggest that this response is quite variable depending on the maize line. Our results showed that the activity of peroxidase reduced in both lines during stress period (Figure 2). However, it has been already reported that ascorbate peroxidase activity increased under salinity stress in Limko, Iman varieties and PEHM 3 and Navgot genotypes of maize plant (Stepien and Klobus, 2005; Kholova et al., 2009). Such a differential variations in the activities of redox enzymes have been numerously reported between the varieties of different plants in response to environmental stresses. Since it is generally accepted that there is a correlation between the increased activity of the redox enzymes and the stress tolerance, it seems likely that peroxidase may not be involved in salt resistance phenomenon in the maize lines A-180 and A-619.

Here we also report the increased activity of polyphenol oxidase during salt stress in these maize lines (Figure 2). Polyphenolic compounds such as phenolic acids, flavonoids, anthocyanins have been already found to play an important role in scavenging free radicals produced during salt stress in plants (Parida et al., 2004; Ksouri et al., 2007; Hichem et al., 2009). The antioxidant activity of phenolic compounds is mainly due to their redox properties, allowing them to act as reducing agents, hydrogen donors and singlet oxygen quenchers (Beckman, 2000). They are implicated in response to different abiotic stresses (Beckman, 2000). Polyphenol oxidase is one of the polyphenolic compounds redox catalyzing enzyme and the induction of its activity under salinity indirectly could indicate the involvement of antioxidative polyphenols in salt-challenged plants.

The present study revealed that the activities of catalase, peroxidase and polyphenol oxidase undergoes a differential modulation (increasing or decreasing) upon salt stress while the total antioxidative status was consistently increased during the stress and slowly declined during recovery period. Are these differential activation patterns related to their differential contribution in salt resistance mechanism? This is an issue that needs to be further explored in the future.

The enzyme phenylalanine ammonia lyase (PAL) catalyzes deamination reaction of the amino acid phenyl alanine at the gateway from the primary metabolism into the important secondary phenylpropanoid / phenolic metabolism in plants (Hahlbrock and Scheel, 1989). Effects of different stresses on PAL activity has been previously reported (Dixon and Paiva, 1995; Ritter and Schulz, 2004; Gholizadeh et al., 2004).

Here we showed that the activity of PAL increased quickly during one day salt stress period in both maize inbreds (Figure 3). After the stress period, is observed a partial decrease in the stress-induced PAL activation found in both inbreeds during recovery time.

The overall pattern in the activity of the PAL enzyme showed similarity to the total anitioxidation pattern in these maize plants suggesting that PAL could be a component of pivotal importance in this salt-induced maize antioxidative system.

The results indicated that the activation of the antioxidant system is quite variable in maize plants, and restate the question: How much does antioxidation strategy help to salt resistance in maize? Nevertheless, the data clearly indicates that the PAL enzyme can be considered as a new candidate for maize genetic engineering towards the salt resistance.

Acknowledgments: The authors of this paper are thankful to RIFS (Research Institute for Fundamental Sciences), University of Tabriz, Iran, for funding this work.

\section{REFERENCES}

Abel AJ, Sutherland MW, Guest DI (2003) Production of reactive oxygen species during non-specific elicitation, non-host resistance and field resistance expression in cultures of tobacco cells. Func. Plant. Biol. 30: 91-99.

Adam AL, Bestwick B, Barna B, Mansfield JW(1995) Enzymes regulating the accumulation of active oxygen species during the hypersensitive reaction of bean to Pseudomonas syringae pv. Phaseolicola. Planta 197: 240-249.

Alscher RG, Donahue JL, Gramer CL (1997) Reactive oxygen species and antioxidants; relationships in green cells. Physiol. Plant 100: 224-356.

Asada K (1994) Production of active oxygen species in photosynthetic tissue, In: Foyer $\mathrm{CH}$, Mullineaux PM (eds) Causes of photooxidative stress and amelioration of defense system in plants. CRC, Boca Roton, 77-104.

Beckman CH (2000) Phenolic storing cells: keys to programmed cell death and periderm formation in wilt disease resistance and in general defense responses in plants? Physiol. Mol. Plant. Pathol. 57: 101-110.

Benzie FF, Strain JJ (1999) The ferric reducing ability of plasma as leisure of antioxidant power, The FRAP assay. Anal. Biochem. 239: 70-76. 
Bestwick CS, Adam AL, Puri N, Mansfield JW (2001) Characterisation of changes to pro and antioxidant enzyme activities during the hypersensitive reaction in lettuce (Lactuca sativa L.). Plant Sci. 161: 497-506.

Blokhina 0, Virolainen E, Fagerstedt KV (2003) Antioxidants, oxidative damage and oxygen deprivation stress. A review. Ann. Bot. 91: 179-194.

Desikan R, Mackerness AHS, Hancock JT, Neill SJ (2001) Regulation of the Arabidopsis transcriptome by oxidative stress. Plant Physiol. 127:159-172.

Dionisio-Sese KL, Tobita S (1998) Antioxidant responses of rice seedlings to salinity stress. Plant Sci.135: 1-9.

Dixon RA, Paiva NL (1995) Stress-induced phenylpropanoid metabolism. Plant Cell. 7: 1085-1097.

Gholizadeh A, Kumar M, Balasubramanyam A, Sharma S, Narval S, Lodha MI, Kapoor HC (2004) Antioxidant activity of antiviral proteins from Celosia cristata L. J. Plant Biochem. Biotech. 13: 13-18.

Gholizadeh A, BaghbanKohnehrouz B, Hekmatshoar H (2007) Step-by Step morpho-physiological responses of Arachis hypogaea L. cv NC.2 to iron deficiency. Plant Soil Environ. 53: 290-298.

Gomez JM, Jimenez A, Olmos E, Sevilla F (2004) Location and effects of longterm $\mathrm{NaCl}$ stress on superoxide dismutase and ascorbate peroxidase isoenzymes of pea (Pisum sativum cv. Puget) chloroplasts. J. Exp. Bot. 55: 119-130.

Gossett DR, Millhollon EP, Lucas MC (1994) Antioxidant response to NaCl stress in salt-tolerant and salt-sensitive cultivars of cotton. Crop Sci. 34: 706-714.

Hahlbrock K, Scheel D (1989) Physiology and molecular biology of phenylpropanoid metabolism. Ann. Rev. Plant Physiol, Plant Mol. Biol. 4: 347-369.

Heidari M (2009) Antioxidant activity and osmolyte concentration of Sorghum and Wheat genotypes under salinity stress. Asian J. Plant Sci. 1-5.

Hernàndez JA, Ferrer MA, Jiménez A, Ros-Barceló A, Sevilla F (2001) Antioxidant system and $\mathrm{O}_{2}$ and $\mathrm{H}_{2} \mathrm{O}_{2}$ production in the apoplast of Pisum sativum $\mathrm{L}$. leaves; its relation with $\mathrm{NaCl}$-induced necrotic lesions in minor veins. Plant Physiol.127: 817- 831 .

Hichem H, Mounir D, Naceur A (2009) Differential responses of two maize varieties to salt stress: changes on polyphenols composition of foliage and oxidative damages. Indust Crops Prod. 30: 144-151.

Kholova J, Sairam RK, Meena RC, Srivastava GC (2009) Reponse of maize genotypes to salinity stress in relation to osmolytes and metal-ions contents, oxidative stress and antioxidant enzymes activity. Biol. Plant. 53: 249-256.

Ksouri R, Megdiche W, Debez A, Falleh H, Grignon C, Abdelly C (2007) Salinity effects on polyphenol content and antioxidant activities in leaves of the halophyte Cakile maritima. Plant Physiol. Biochem. 45: 244-249.

Larson RA (1988) The antioxidants of higher plants. Phytochem. 27: 969-978. Lee DG, Ahsan N, Lee SH, Kang KY, Bahk JD, Lee I.J, Lee BH (2007) A proteomic approach in analyzing heat-responsive proteins in rice leaves. Proteomics 7 : 3369-3383.

Misraa N, Guptab AK (2005) Effect of salt stress on proline metabolism in two high yielding genotypes of green gram. Plant Sci. 169: 331-339.
Mittler R (2002) Oxidative stress, antioxidants and stress tolerance. Trends Plant Sci. 7: 405-410.

Munns R (2002) Comparative physiology of salt and water stress. Plant Cell Environ. 25: 239-250.

Niknam V, Razavi N, Ebrahimzadeh H, Sharifizadeh B (2006) Effect of NaCl on biomass, protein and proline contents, and antioxidant enzymes in seedlings and calli of two Trigonella species. Biol. Plant. 50: 591-596.

Okada Y, Okada MJ (1998) Scavenging Effect of Water Soluble Proteins in Broad Beans on Free Radicals and Active Oxygen Species. J. Agri. Food Chem. 46: 401-406.

Parida A, Das AB, Sanada Y, Mohanty P (2004) Effects of salinity on biochemica components of the mangrove Aegiceras corniculatum. Aqua. Bot. 80: 77-87.

Rental MC, Lecourieux D, Ouaked F, Usher SL, Petersen L, Okamoto H, Knight $\mathrm{H}$, Peck SC, Grierson CS, Hirt H, Knight MR (2004) OXI1 kinase is necessary for oxidative burst-mediated signaling in Arabidopsis. Nature 427: 858-861.

Ritter H, Schulz GE (2004) Structural bases for the entrance into the phenylpropanoid metabolism catalyzed by phenylalanine ammonia lyase. Plant Cell 16: 3426-3436.

Rout NP, Shaw BP (2001) Salt tolerance in aquatic macrophytes: possible involvement of antioxidative enzymes. Plant Sci.160: 415-423.

Sadasivam S, Manickam A (1992) Biochemical methods for agricultural Sciences, Wiely Eastern Limited, New Delhi

Saleh L, Plieth C (2009) Fingerprinting antioxidative activities in plants. Plant Meth. 5: 2.

Schleiff U (2008) Analysis of water supply of plants under saline soil conditions and conclusions for research on crop salt tolerance. J. Agro. Crop Sci. 194: 1-8.

Shao HB, Chu LY, Lu ZH, Kang CM (2007) Primary antioxidant free radical scavenging and redox signaling pathways in higher plant cells. Int. J. Biol. Sci. 4: 8-14.

Siddique M, Sinha NK, Cash JN (1992) Characterization of polyphenoloxidase from Stanley plums. J. Food Sci. 57: 1177-1179.

Sreenivasulu N, Grimm B, Wobus U, Weschke W (2000) Differential response of antioxidant compounds to salinity stress in salt-tolerant and salt-sensitive seedlings of foxtail millet (Setaria italica). Physiol. Plant 109: 435-442.

Stepien P, Klobus $G$ (2005) Antioxidant defense in the leaves of $\mathrm{C}_{3}$ and $\mathrm{C}_{4}$ plants under salinity stress. Physiol. Plant 125: 31-40.

Tsugane K, Kobayashi K, Niwa Y, Ohba Y, Wada K, Kobayashi H (1999) A recessive Arabidopsis mutant that grows photoautotrophically under salt stress shows enhanced active oxygen detoxification. Plant Cell 11: 1195-1206.

Yoda H, Hiroi Y, Sano H (2006) Polyamine oxidase is one of the key elements for oxidative burst to induce programmed cell death in Tobacco cultured cells. Plant Physiol. 142: 293-206.

Young CB, Jung J (1999) Water-induced oxidative stress and antioxidant defenses in rice plants. J. Plant Physiol. 155: 255-261. 